\title{
A New Material Used in Adsorption of Hazardous Chemical Oil Spill and the Risk Analysis of the Related Contingency Plan
}

\author{
Jianshe Huang ${ }^{1}$, Wujun $\mathrm{Hu}^{2}$, Ying Huang ${ }^{3}$, Lina Chen ${ }^{2}$, Zhimin $\mathrm{Jin}^{4, *}$ \\ ${ }^{1}$ Yongkang Zhong-Yi Industry and Trade Co., Ltd, Yongkang 321300, China \\ ${ }^{2}$ Yongkang pesticide factory, Yongkang 321300 , China \\ ${ }^{3}$ Yongkang Research Institute of Harmonious Thought, Yongkang 321300, China \\ ${ }^{4 *}$ College of Pharmaceutical Sciences, Zhejiang University of Technology, Hangzhou 310014, \\ China,
}

\section{油污危化品泄漏吸附新材料及应急预案风险分析}

\author{
黄建社 ${ }^{1}$, 胡武军 ${ }^{2}$, 黄 颖 $^{3}$, 陈丽娜 ${ }^{2}$, 金志敏 ${ }^{4, *}$ \\ '永康市中翼工贸有限公司, 永康 321300 , 中国 \\ ${ }^{2}$ 永康市农药厂, 永康 321300 , 中国 \\ ${ }^{3}$ 永康市和谐思想研究会, 永康 321300 , 中国 \\ “*浙江工业大学, 杭州 310014, 中国
}

\begin{abstract}
In this paper, a novel inert polymer adsorption material for hazardous chemical oil, named as Zhong-Yi FG strong adsorption material, is proposed in emergency disposal to deal with pollution of sudden chemical spill into rivers and oceans, and to recover chemical leakage. In this paper, a simple and convenient emergency treatment technology is proposed for handling chemical oil spill accidents. Compared with traditional adsorption materials and related emergency plans, this novel adsorption material and its related emergency plan have made remarkable progress in improving the ability of emergency management.
\end{abstract}

*作者简介: 金志敏, 男, 1963 年, 博士, 浙 江工业大学, 教授, EMAIL:zimichem@sina.com, 邮编: 310014, 联系方式: 13375810946

\begin{abstract}
Keywords: adsorption materials; secondary disasters; hazardous chemicals; contingency plans; risk analysis

摘要

本文提出了一种新型的油污危化品吸附新 材料-中翼 FG 高分子惰性强吸附材料, 用 来应对因化学品泄漏河流、海洋中产生的 应急处置和污染恢复, 具有更好的环境保 护作用。本文还提出了一种简易的溢油应 急处置技术方案, 用来应急处置化学物质 的泄漏事故。通过与传统吸附材料和应急 预案的对比, 说明本文介绍的吸附材料和 应急预案能对提高应急管理能力具有显著 作用。
\end{abstract}

关键词：吸附材料；次生灾害；危化品； 应急预案; 风险分析 


\section{1. 引言}

河流海洋中的化学物质泄漏对人类健 康和水生环境构成重大威胁 ${ }^{[1]}$ 。打好污染防 治攻坚战, 是中国政府提出的全面决胜小 康社会的重要战役 ${ }^{[2]}$ 。油类、芳烃类等化学 溶剂泄漏应急预案, 是预防海上船舶作业 以及生产和储运过程中应对各种突发泄漏 污染事故的关键策略。应急预案不当所产 生灾害风险就越大, 缺乏完善应急预案与 应对技术措施是引发次生事故根源, 结合 我国应急预案风险防范体系上还存在不少 的认识盲区, 相应缺乏应对突发事件整个 周期全方位系统性防范措施, 灾后缺泛传 播防微杜渐应急科普理论宣传。保护环境 加快资源节约型、环境友好型社会建设是 国家的基本国策。

本文介绍一种中国发明专利产品 - 吸 附化学泄漏的 FG 高分子惰性复合材料 ${ }^{[3]}$ 。 从理论与实践证明, 该材料化学性质稳定, 无害无毒、无味、耐高温、无氧化性、无 腐蚀性等理化性, 对 5100 多种油类及化学 液体具有不可逆强吸附作用。水面泄漏应 急处置过程中, 能够快捷达到彻底吸附泄 漏物及灭火防爆的优异效果, 持油性好, 封 锁污染物及重金属, 有效控制污染源扩散 渗透, 填补应急领域惰性复合材料的空缺, 降低和避免应急措施不当产生次生灾害、 污染环境事故的风险, 对科学污染防治具 有重要理论和实践意义 ${ }^{[4]}$ 。

该新材料技术; 在危管防污应急治理 上可在一定程度上有效避免次生灾害和二 次污染, 对海洋水域生物无害无毒环境友 好, 可节约 $90 \%$ 人工费和 $80 \%$ 材料成本 ${ }^{[5]}$ 。

从中填补传统应急预案储备物资中的 缺项; 因 PP 吸油毡、PP 吸油拖栏、PP 吸 油棉、植物吸附剂、活性炭、消油剂、收 油机等设施在使用过程中成本居高难下、 油污难以彻底清除、易燃易爆、容易次生 灾害、危害环境安全等难题和弊端。

该新材料技术; 控制船舶港口突发溢 油火灾、水面油火险情曼延, 起到吸附、 灭火、阻截多重功效。可广泛应用于海事 船舶应急领域、危化品港口码头、交通道 路运输、大型油库防泄漏、防火、防爆应
急控制处置、工矿企业油污水分离、防灾、 减灾等环境危害专项应急治理。已获中国 发明专利 1 项, 外观专利 3 项。

\section{2. 溢油危化品吸附材料背景技术}

2017 年中国海关总署统计原油进口量 4.2 亿吨, 这是我国首次超过美国成全球最 大石油进口国。原油进口船运给中国带来 的溢油应急风险成为海洋环境污染的重大 风险要素。党的十九大提出要打好重大风 险防范和污染防治以及扶贫脱困三大攻坚 战, 其中把污染防治列为攻坚战来部署耐 人寻味。至少表明了国家对环境污染的现 状已到了不能容忍的程度。宪法已经增加 了国家要重视生态建设和五大生态理念的 内容。

众所周知, 海上船舶运输的石油类、 芳烃类、化学溶剂类以及生产、储存、运 输过程的跑冒滴漏、泄漏等现象大量发生, 由于应急预案陈旧, 处置技术能力不足, 很容易引起次生重大环境灾害。就连内陆 一些环保措施较完善的大型工矿企业, 由 于应急预案落后, 处置物资储备不足、技 术设施落后, 危化品泄漏事故也屡见不鲜, 导致生态环境严重破坏与次生灾害重大事 故频发, 引发群体事件影响社会和谐安定。

目前油类危化品应急吸附材料的应用 还存在误区: 例如, 消油剂、扩散机、作 为限制使用的应急物资 ${ }^{[6]}$ 。消油剂在国际上 早已经被禁止在淡水和近按海域使用, 可 是国内仍有应急部门当做主要溢油清除措 施, 不少大型石化企业和海事溢油储备库 至今还大量储存采购。据研究, 消油剂的 大量私自使用, 使溢油融解海水之中, 海 水中的芳烃类微粒以水、气、热等循环蒸 腾和挥发途径, 向大气层转移, 形成雾䨪 产生的源头之一。不少码头、船舶的防泄 漏吸附材料是一些易燃品, 没有从灭火防 爆的要求出发。军事用途的船舶维修和涂 装产生的废弃物污染海水的监管缺失。

虽然传统应急材料产生的次生灾害, 一般来说要大于应急现场事故所造成的危 害。但是令人无奈的是, 这些落后治理方 法在溢油处理上还在普遍沿用。如合成有 
机聚丙烯 PP 喷融无纺布吸附材料及纤维 棉布，使用成本较高，遇明火易燃，产生 有毒烟气，在治理液态易燃、易爆的危险 物品泄漏事故时、不仅严重污染环境，而 且威胁了人类的健康安全, 危及无公害后 处理。

目前有些国家又研制出运用如树皮、 海藻、锯末等废物利用新型吸附材料, 较 之 PP 棉产品有了很大的进步, 但是仍然存 在易燃易爆的缺陷、遇到水面溢油失火的 场景就无法治理。

\section{3. 一种新型的油污危化品吸附新材料一中 翼 FG 高分子惰性强吸附材料}

该材料用于溢油应急上具有油水分离 性好, 物理不可逆吸附、持油性能好等显 著特点。适合用于应急防治芳烃类、燃油 类、化学溶剂类 (甲苯、氯苯、二甲苯、 乙基苯、六氯苯、苯酚、环己烷、邻苯二 甲酸二辛酯、甲醇、乙醇、汽油、柴油、 机油、齿轮油）等泄漏污染物以及重金属 泄漏事故控制, 起到强吸附、强固定、兼 具灭火防爆等救灾防灾减灾作用。

其超强吸附原理是; 高分子复合 FG 吸 附颗粒为惰性吸附材料, 无毒无害, 耐高 温 800-1500C0, 耐低温零下 50C0, 化学性 质稳定, 无氧化作用, 耐酸碱耐腐蚀, 不 燃。其颗粒有着特殊纳米微细孔空隙结构 组织, 吸储孔隙发达, 比表面积大, 微孔 组织构造有超强的物理吸附力场, 吸附速 率快, 持油性好, 吸附污染物打捞后遇雨 水不会稀释溢出, 阻止污染物渗透扩散, 避免二次污染汇入次生灾害。

该材料技术适用于海洋或水面化学溶 剂污染应急预案与应急治理; 纯物理吸附 模式, 应急处置过程中无任何化学反映, 处置后水面立即恢复原有的洁净状态, 所 以对水生鱼类不会产生任何不利影响, 解 决传统预案中化学洗消方式容易次生危害 水生鱼类、藻类等水生植物、污染水域环 境的一大难题。

该材料技术用于应急治理交通道路危 化品、油污泄漏预案上, 不但储运轻便, 后处理成本低, 吸附溢油后无须水清洗, 将事故消除萌发期, 赢取最佳防范时机,
制止污染源扩散。若在应急处理交通道路 意外泄漏事故中, 遇撒布路面的吸附砂垫 来不及清理, 可先让车辆车轮辗压通行, 因其摩擦系数大, 还能起到防滑作用, 消 除交通隐患, 确保道路畅通。

该吸附材料用于化学溶剂生产、仓储、 加油站应急预案储备上, 备而无患; 可根 据不同场景制成不同形态 $F G$ 吸附垫置放于 化学溶剂管道阀门正下方, 吸附跑、冒、 滴、漏下的少量化学溶剂泄漏物, 能有效 避免储罐化学溶剂泄漏物污染地下水源、 地表水域环境。遇地面泄漏物不慎起火时, 用 FG 吸附颗粒防污治理可起到室息氧气阻 断火源, 制止火情蔓延, 起到预想不到的 效果。

在挥发性较大的芳烃类化学溶剂的生 产储存场所内使用高分子复合 $\mathrm{FG}$ 吸附包防 污治理; 能够快速净化游离室内各种有毒、 有害污染气体, 保障生产、储存场所环境 安全。高分子复合 FG 吸附包使用后、可经 阳光暴晒脱附处理后重复使用。

该材料用于应急抢险后置处理成本低; 可将已吸附芳烃类化学溶剂脱附回收, 脱 附后的高分子复合 FG 吸附剂颗粒经处理后 还可重复使用。遇吸附油类清除打捞的废 弃物会呈固体状、方便装袋打包运输无害 化处理, 吸附有关化学有毒危险物品的固 废按政府规定法规处理。

\section{G25 长深高速永康段 18 吨机油泄漏永祥 溪重大事故应急处置成功案例评估}

2016 年 7 月份炎夏, 浙江省 G20 杭州 峰会筹备活动正紧张有序开展。15 日凌晨, G25 长深高速公路 (金丽温) 永康段, 毫无 征兆蹊跷地发生了一起 18 吨润滑油泄漏钱 塘江水系源头一永祥溪的特大突发事故。如 果处置不当, 油污泄漏到富春江、钱塘江, 无疑会产生极其恶劣的社会影响。临危受 命的永康市中翼环境污染治理队、千禧救 援队、先锋水上救援队等社会救援组织, 采用了先进的吸附材料, 运用了科学的应 急方法, 义无反顾地参加了由政府主导的 大型化学污染应急救援活动; 从 7 月 15 日 7 时 50 分接受应急联动指令起至 9 月底结 束, 历经 75 天, 依照完善应急预案与先进 
技术, 完全控制次生灾害爆发, 做好事前、 事中、事后全程油污防控清除、土壤治理 恢复工作。

中翼公司研发的这一省级新产品项目, 在通过浙江省科技局组织的专家验收以后, 再次从实践验证了 FG 高分子吸附材料用于 应急领域所预料不到的社会效果。事故发 生后 3 个月来, 永康市有关部门, 多次对 受污染水域环境进行水质监测及长期观察, 均未发现永祥溪因此次事故对下游水质及 武义江水域综合环境造成不良影响。

政府重视应急管理; 作者以亲身经历 深刻体会到, 事实证明, 金华市、永康市 应急办领导的 2016-7-15 特大溢油事故应 急抢险活动是极其成功的, 是由政府主导、 部门协作、社会参与应急联动的实践创新, 是相信群众依靠群众取得胜利的典范, 也 是一次将科学创新技术用于溢油应急处置 而圆满成功的范例。

特别值得一提的是, 金华市应急办祝 副主任、永康市应急办童副主任等应急联 动的负责同志, 在特大溢油突发事故发生 后, 第一时间启动应急预案; 给中翼救援 队下达应急响应指令; 并身先士卒以身作 则亲临现场, 与各部门密切协作团结作战 发挥了重要作用。特别是有关应急办各级 领导, 在危急关头敢于抛弃传统落后的应 急预案旧思维, 勇于担当, 勇担责任, 大 胆拍板, 顶住压力, 启用先进的中翼溢油 危化品吸附新材料和新技术, 切实保护了 下游金华江、兰江、富春江、钱江水系水 域环境的安全, 避免溢油应急措施不当导 致次生特大环境危害事故, 为保障 G20 杭 州峰会的胜利召开作出了杰出贡献。

社会组织专业救援队伍: 此次 G25 长 深高速公路 (金丽温) 永康段特大溢油事 故, 之所以大胆采用了中国的发明专利惰 性吸附材料技术, 使用社会力量以最小的 人力、物力取得了圆满的成功, 政府应急 管理部门的应急创新居功至伟。金华市应 急办与永康市应急办原筹备计划 7 月 15 日 在永康开展 “护航” G20 综合实战演练暨应 急力量检验活动, 后因故推迟 20 日举行。 永康中翼应急队自接到参加演练通知后、
配备物资时刻待命, 恰巧真的遇上七・五突发溢油事故, 一声指令即刻响应, 奔 赴现场, 快速化解险情。应了一句俗语叫 天佑中华。

应急物资保障: 浙江金华市永康（中 翼) 环境污染治理应急救援队接到省市应 急办险情通报后, 组织 30 余名救援人员奔 赴现场, 投放吸附材料 9.78 吨, 按照应急 预案开展 8 昼夜抢险, 针对水面油污围追 堵截, 布控高分子复合 $\mathrm{FG}$ 吸附拖栏, 将油 污严格控制在该河段 1000 米上园水坝内, 按照处置预案, 合计投放高分子复合 FG 吸 油拖栏 360 米, FG 吸油颗粒 6.62 吨、FG 吸油垫 1.54 吨, 从事发 7 月 15 日 8 时起 至 9 月底结束, 累计清除油污河段约长 1000 余米、水域面积约 2 万平方米。清理 高速公路路坡约 300 平方米; 清理及改良 受污染的农林田地约 1.3 万平方米, 全程 采用物理吸附模式将油污彻底清除, 累计 打捞油污废弃物达 30 余吨作无害化处理。

应对决策科学: 完善应急预案, 配备 应急资源, 及时评估溢油次生危害风险, 应对技术先进。7.15 油污处置过程中未使 用任何化学品消油剂, PP 吸油棉等传统材 料, 全程选用新型高分子复合 FG 吸附材料 $9.78 \mathrm{t}$, 化解洪水来袭油污泄流险情, 确保 下游富春江、钱塘江水域环境、水生渔类、 植物的安全, 此举打破国内外溢油环保模 式治理的新纪录。2016 年 12 月 8 日, 永康 市中翼工贸有限公司应邀参加了在中国北 京召开的第五届国际溢油技术交流大会。 得到与会各国专家肯定和高度评价, 此次 “7.15”事故所采用环保模式应对防灾、 减灾成功典范应急活动的纪实纪实文章约 一万多字, 在会议显著位置作了展示。

此次应急救援活动为 G20 杭州峰会的 安全作出了贡献, 永康市朱市长和人大常 委会陈主任专程对参与应急救援的有关组 织和队伍进行了慰问。

值得一提的是, 来自永康市第一线优 秀工人全国人大代表的黄女士, 在了解情 况以后, 认为有必要从立法层面解决应急 保障机制问题, 在出席第十三届全国人大 会议期间, 提交了有关要修改突发事件应 
对法的立法建议, 要完善社会应急救援组 织应急保障机制的立法议案。引起全国多 家媒体的报道及国务院领导的重视。

总结经验与教训: 永康 7-15 特大溢油 事件, 如果仍沿袭传统应急预案与应对措 施, 依旧如 2011-6-4 杭新景高速公路苯酚 泄漏时用石灰中和、砂土填埋、清水大量 冲洗等落后应对预案, 现场可能 1 个小时 就处置完毕, 应急办也不会由此承担什么 责任。但是随着时间的推移, 兹生的二次 污染和次生灾害, 必然就会毫不留情地展 现出来。那时与永祥溪永康江、金华江、 兰江一脉相传的富春江和钱塘江就会大量 漂浮褐兰色的油污, 富阳桐庐两岸民人以 及沿江生态和美丽环境都会深受其害。更 可怕的是, 毫无疑问会被在 G20 杭州峰会 采访的世界各国一千多名记者关注报道, 有可能给国家造成不可估量的政治经济上 的巨大损失。所以, 应急技术的科学创新, 事关大局, 刻不容缓。

\section{5. 我国泄漏事故应急预案落后导致次生灾 害及环境污染的风险分析}

应急管理部副部长黄明同志, 在今年 6 月 11 日主持部长办公会议时指出: “要以 极端认真负责的态度深入查找问题根源, 对每起重特大事故、影响较大的事故都要 从企业操作规程指定、执行、监督和安全 教育培训等环节入手, 彻查原因, 严防流 于形式、浮于表面。要以极端认真负责的 态度抓整改, 对照问题制定更准更细更实 的措施, 并警示相关企业引以为戒、改进 提高, 防止类似事故重复发生”。

钱洪伟曾指出, 应急是安全管理全过 程; 灾害是突发事件的社会影响性; 风险 是突发事件之前的管控、危机是突发事件 严重化。应急科学主要采用科学措施研究 突发事件发生之前、之中及之后整个周期 过程的全方位、系统性防范与应对的规律、 策略 ${ }^{[7]}$ 。

为此, 本文试图根据媒体公开的国内 几起重大溢油污染环境的典型事故案例, 通过分析其应急处置的问题根源及对环境 的影响和风险进行科学评估, 以供应急科 学工作者研讨。

\section{1 中石油吉林石化泄漏爆炸案例}

2005 年 11 月 13 日, 中石油吉林石 化公司双苯厂发生爆炸导致 6 名工人失踪, 受伤人员近 70 人, 发生多次爆炸的是该厂 苯胺装置硝化单元, T-102 塔发生堵塞, 循 环不畅, 工人后续处理不当发生爆炸。当 日首次爆炸波及其他装置发生泄漏, 继而 发生爆炸 15 起, 其中较大的爆炸 6 起。附 近上万居民被紧急疏散。[8]

当时, 根据预案而采用传统易燃物 PP 喷融棉对泄漏液体进行吸附, 至发生闪爆引 发爆炸, 导致泄漏源扩大, 产生连锁爆炸 反应。导致大量化危品泄漏, 便采用石灰 中和、砂土填埋等处理。当时应急处理后 表象正常。但 4-7 天后, 发生次生灾害和 二次污染。监测发现苯类污染物流入松花 江, 给沿江城市用水造成水质严重污染, 给大马哈鱼的生态也造成重大影响。

我国类似化工厂大型储液槽罐设备老 化, 管道腐蚀等原因也常常导致发生危险 化学品泄漏严重危害环境事故。

应急预案风险分析: 这是一起早期的典 型的应急预案落后导致的重大环境灾害风 险发生的案例。可惜, 当年没有引起专业 应急管理部门以及相关环保部门的重视, 当时普遍认为出现特大化学污染事故时, 尚没有好的办法来保护环境不受损害的; 对事故现场的人身安全保护是第一位的, 环境保护是次要的, 甚至可以忽略不计的。 所以, 并没有在应急科学管理上做文章, 仅从行政职能方面去追究有关官员的责任。 错过了举一反三如何提高应急管理科学水 平的机会, 巨大的代价并没有换取教训和 提升应急科学管理水平。

应急科学防范应对建议: 遇到类似化 工泄漏事故时：第一步, 应急人员必须穿 戴防毒面具, 第一时间采用灭火防爆的惰 性物理吸附材料 (惰性 FG 吸附颗粒剂、吸 附垫、吸附拖栏、吸附棒等), 就近把泄 漏的化工易燃易爆液体围堵、吸附、覆盖, 使之液体变固, 易燃变不燃, 将泄漏危机 风险迅速控制。注意, 切不可以用管道将 其排入暗管或进入公共管道, 以避免扩大 污染源。第二步, 如果遇失火爆炸的情况, 
也不可随意用水冲洗或造成污染源或流淌 火势扩大; 而是应该将前述惰性物理吸附 材料, 铺撒在泄漏液体的周边进行围堵以 防危机扩大。第三步, 必要时应该在安全 距离挖堵截沟, 内填灭火防爆强吸附的惰 性吸附材料, 可以有效地将泄漏的化学危 化品拦截, 以防向周边扩污染源, 有效阻 截火势范围。第四步, 确认泄漏源被控制 后, 将吸附材料用防静电工具清扫装袋回 收。后处理无害化措施, 须严格按所泄漏 物化学性质, 制定适当的技术方法处理。

结论: 应急预案要不断更新, 掌握专 业应对策略技术, 至少所有化学液体生产 和储备场所, 现场必须配备储备一定量防 火防爆的惰性吸附材料, 禁止使用易燃吸 附材料, 落实事前、事中、事后全方位系 统性防范措施, 才能确保现场人身安全, 制止或避免引发次生灾害和二次污染对环 境的灾难。

\section{2 杭新景高速槽罐车苯酚泄漏案例}

2011 年 6 月 4 日 22 点 55 分左右, 一 辆装载有化学品苯酚的槽罐车, 在由上海 开往浙江龙游的途中, 经杭新景高速公路 新安江高速出口互通主路段内（S31 龙游方 向 48 公里+200 米处) 时发生车辆追尾事故, 导致部分苯酚泄漏。建德市、杭州市两级 政府立即启动突发环境事件应急预案, 赶 赴现场进行处置; 对泄漏的苯酚用石灰进 行酸碱中和方法处置, 截至 6 月 5 日中午 12 时发生交通事故的现场始清理完毕。媒 体报道称残留在现场的部分苯酚得到清除。 不幸的是, 更大的次生灾害发生在应急处 置 4-5 天以后: 事故发时正逢暴雨影响, 导致大部分泄漏苯酚高毒物质随雨水径流、 土壤渗透污染新安江, 造成部分水体受到 严重污染。造成桐庐、富阳 5 家水厂 35 万 吨日供水量停止取水, 45 万人口饮用水受 到污染。其他生态影响不可估量。此事件 引起省委领导高度重视, 为了确保新安江 下游用水安全, 新安江大坝加大泄洪水量, 加速水体更新 $[9]$ 。

应急预案风险分析：据事后专业人士 分析: “其实应急处置只是清除了高速公 路的苯酚, 而且任由苯酚流入周边泥土层。
真实情况, 苯酚残液并没有按规定固态封 锁彻底消除。因为当时没有适当的应急物 资储备计划, 也就无法采用惰性固体防火、 防爆吸附材料进行防堵作业。所以应急处 置人员为了尽快恢复交通减少负面影响, 采用传统预案措施, 将石灰与苯酚中和洗 消方法处理, 中和的石灰虽然回收, 但导 致冲洗液以渗透污染到周边土壤深层, 在 暴雨径流方式污染到富春江。

事后应急部门也没有对次生环境危害 风险及时作出评估, 以致污染源渗透扩散, 引发次生灾害, 直接危及到离案发地 5 公 里外新安江水系环境, 造成直接经济损失 至少数十亿元人民币。其实这些落后的洗 消方法在日本及西欧、美欧国家，法律法 规上是禁止的, 我国危管防污法律法规、 应急预案、处置策略对此没有明确规定, 有待不断完善修正。

应急科学防范应对建议: 正确的预案 技术措施应当是这样的: 第一步, 应急人员 穿戴预防苯酚中毒的防护服装, 用惰性强 吸附材料迅速覆盖所有泄漏苯酚的路面, 迅速将苯酚液体以物理吸附方式回收, 装 袋。这样很快可以恢复交通。

第二步, 观察苯酚泄漏到周边土壤和 泄流管道的情况。迅速在泄漏区域之外至 少 10 米处, 挖掘深沟, 深沟的宽度和深度 应该合理判断土层的结构, 在沟内填埋高 分子惰性吸附颗粒或吸附垫, 围堵渗透泄 漏的苯酚, 预防扩散危害周边环境。若将 污染源有效的控制, 即使遇上大暴雨, 苯 酚立即就会被惰性吸附材料吸附、封锁, 吸附成固态状, 避免因渗漏导致次生灾害。 事后待确保安全方可将吸附材料回收作无 害化处理。

结论和教训: 当时若有应急预案技术 与次生灾害防范措施物资, 那么, 远离事 发地 5 公里之外的新安江富春江的水源就 不会受到危害。可惜的是, 该事故发生以 后, 媒体和政府应急管理部门关注的焦点 是, 新安江水源不应该有危化品运输车辆 出现, 却很少有人从完善应急科学管理角 度探讨。正如应急管理部黄明副部长说的 那样, 迫在眉睫的是如何提升我国应急管 
理科学技术水平、更新应急预案的技术含 量, 完善防范污染和善后环保等决策等方 面去考虑问题。可见, 应急管理部门与应 急救援部门存着跨越式思维鸿沟, 亟待磨 合与改进。

\section{3 蓬莱钻井平台溢油污染海洋案例}

蓬莱 19-3 油田溢油事故损害情况; 中新网 2012 年 6 月 21 日电 国家海洋局今 日在其官方网站公布《蓬莱 19-3 油田溢油 事故联合调查组关于事故调查处理报告》。 报告披露了溢油事故损害索赔情况: 海洋 生态损害索赔方面, 康菲公司和中海油总 计支付 16.83 亿元人民币, 其中, 康菲公 司出资 10.9 亿元人民币, 赔偿本次溢油事 故对海洋生态造成的损失。

海洋生态损害索赔。评估结果表明, 溢油事故造成的海洋生态损害价值总计 16.83 亿元人民币, 主要包括海洋环境容量 损失、海洋生态服务功能损失、海洋生境 修复、海洋生物种群恢复费用等。

至 2012 年 4 月, 国家海洋局北海分局、 康菲公司、中海油共同签订了海洋生态损 害赔偿补偿协议。康菲公司和中海油总计 支付 16.83 亿元人民币, 其中, 康菲公司 出资 10.9 亿元人民币, 赔偿本次溢油事故 对海洋生态造成的损失。中海油和康菲公 司分别出资 4.8 亿元人民币和 1.13 亿元人 民币, 承担保护渤海环境的社会责任 [10]。

应急预案风险分析: 专家分析, 蓬莱 19-3 油田溢油事故之所以造成如此大的环 境污染影响, 其原因有二点。一是溢油事 故发生时, 对溢油危害估计不足, 为了掩 盖真相怕被媒体曝光, 有可能私自采用了 消油剂、扩散剂、生物消油剂进行违规作 业。

而国际溢油组织公约规定: 消油剂只 能在距海岸 200 海浬且风浪大无法采有用 其他收油措施和吸附措施时才可以使用。 众所周知, 消油剂本身也是化学有害品, 消油剂对环境的危害被大大低估。消油剂 并不能将溢油消除, 只能起到在水的作用 下将大颗粒油乳化细化生成微小油颗粒的 作用, 并不能消除油对水生物的毒害, 相 反, 消油剂加剧了油对水生物的毒害。因
为浮油只是对飞鸟有害, 对鱼的损害相对 比较小。可是如果把油化成微小颗粒的话, 就会进融入浮油生物鱼类及水生植物的活 体组织内, 导致死亡和变异, 一旦触岸, 对岸边的鸟类、哺乳动物、两栖类、爬行 类以及植被也会产生极其严重影响。业内 就有句俗语 “消油剂益鸟害鱼”。说明消 油剂是不能用于近海溢油处理的。这也可 以有力解释, 为什么钻井平台溢油大量使 用消油剂后, 会对中国沿海渔场产生巨大 的生态破坏作用的机制原理。对私自扩大 消油剂使用范围, 继而引起严重环境污染 事故的现象, 依法应当受到法律的制裁, 应该引起全社会的关注和舆论监督。

存在次生环境危害风险: 国际、国家 政府明令禁止在淡水和近海浅海使用的消 油剂, 却被改头换名列入政府采购和大型 国企的溢油应急储备库, 仅 2018 年全国至 少约有 2000 余吨进入各种溢油应急储备库。 若一旦案发, 应对水上溢油事故应急处置, 次生我国的海洋及水域环境灾难性悲剧又 会重演。此情此景引应当起广大环保人士 的抵制和担忧。呼吁政府监管部门对公然 违背国际公约的采购储备消油剂的应急单 位进行干预, 对私自使用消油剂的损害海 洋环境的违法行为依法查处, 强化应急管 理, 对应急预案更新换代, 重视专业应急 人员培训, 明令禁止使用消油剂的违法行 为。

应对困境: 海上钻井平台的泄漏事故 一旦发生, 往往具有泄漏时间长, 比较隐 秘不易被发现, 海上风浪气候条件复杂多 变, 常规的吸油毡、收油机难以见效, 很 容易就出现私自使用消油剂的情况。所以, 首先钻进平台的管理部门必须要树立高度 的环保意识和社会责任感, 呼呼全社会为 祖国的蓝天白云而献计献策。

应急科学防范应对建议: 第一步, 一 旦出现钻井平台溢油的迹象, 立即检查锁 定溢油区域。根据海水深度划定溢油效应 范围, 据此投放惰性吸附材料制成的灭火 防爆型吸油拖栏, 将溢油控制在钻井平台 直径 300-500 米保护圈内。该种吸油拖栏 可以无限连接 100 米至 1000 米长以上, 漂 
浮海面耐风浪, 具有 10 吨的拉力, 吸油之 后几个月不会下沉, 无须针固固定, 投放 简便快捷，兼具围堵和吸附油污的能力。 起到 PV 防火围油栏所起不到的作用。

第二步，在投放好的灭火吸油拖栏圈 内, 抛撒惰性吸附颗粒剂进行物理吸附作 业, 一般从上风口将袋口接触水面倾倒即 可, 在水的张力下, 吸附颗粒会自动往有 油污的水面扩散, 使之布满拖栏内, 比投 放 PP-2 吸油毡节省人工 $80 \%$, 节省材料费 $50 \%$ 以上。此时, 油污将会迅速被吸附封锁 在高分子 FG 吸油颗粒内, 且对水生物完全 无毒。一般情况下, 在发生溢油源头未彻 底消除状况下, 可以任其吸油颗粒漂浮海 面、长达几个月也不会下沉。若确定溢油 终止, 即可将围油拖栏范围缩小、用捞网 将吸附饱和的吸油颗粒打捞后, 装袋回收。 如溢油场景续发泄漏, 可反复投放吸油颗 粒将油污清除治理。

\section{6. 结语}

应急管理部副部长黄明, 在 6 月 11 日 召开的部长办公会议上强调: “要深刻汲 取近期事故教训, 从根源上查找问题本质, 举一反三抓整改, 严厉追责不手软, 以对 党和人民极端负责的态度, 抓好安全生产 工作, 切实维护人民群众生命财产安全。 应急管理部要做好编制应急预案、细化工 作手册、制定保障机制三项工作, 要按照 周到、顺畅、管用、便捷的原则, 加强磨 合对接、及时发现问题、不断修订完善, 确保出现突发情况, 第一时间响应, 最快 速度出发, 有力有序有效处置”。为此, 本文理论联系实践, 抛砖引玉, 意在与业 内学者共鸣。如有不当之处, 敬请指正。

\section{Acknowledgements}

We are grateful to Hong-Wei Qian, doctor of philosophy, associate professor, postgraduate advisor, and director of Emergency Rescue Research Institute of Henan University of Science and Technology, for his devoted discussion and timely advice in composing this article.

\section{致谢}

本文得到了应急管理部有关同志及河南理 工大学工学博士/副教授/研究生导师/应急 救援研究所所长钱洪伟等悉心指导。

\section{参考文献}

[1] D. Mccready, J. B. Williams, Risk assessment for a chemical spill into a river, Journal of Risk Analysis and Crisis Response, 3(3): 116-126, 2013.

[2] 李克强, 政府工作报告, 第十三届全国 人民代表大会第一次会议, 国务院网 站, 2018-3.

[3] 黄建社, 黄渘, 一种吸附泄漏芳烃类化 工溶剂用的吸附剂制备方法和应用, 中国发明专利(专利号 2012101665 02.2).

[4] 黄建社,黄颖,胡武军,中翼 FG 化学吸 附颗粒剂泄漏控制新技术, 浙江省石 油和化工, 2013(4):42-46.

[5] 黄建社, 七.一五 G25 长深高速特大溢 油事故抢险纪实, 永康春秋(永康市 委内部刊物), 2017(1):33-41.

[6] 南京海事局, 长江南京段船舶溢油应 急计划，宁政办发【2003】152号.

[7] 钱洪伟, 应急科学与工程学科知识体 系策略-应急科学学初探,灾害学,2018.

[8] 李秀江, 中石油吉林石化发生爆炸, 中 国经济周刊, (45):7, 2005.

[9] 徐晓, 关于苯酚槽罐车泄漏事故处置 情况通报, 浙江在线, 6-6, 2011.

[10] 蓬莱 19-3 油田溢油事故联合调查组, 关于事故调查处理报告，中新网(国家 海洋局官方网站), 6-21, 2012. 